\title{
ELECTRIC FIELD EFFECT IN THE FORMATION OF WATER TREEING IN MV POWER CABLES
}

\author{
Aluru Divya Teja ${ }^{1}$, K. Rajagopala ${ }^{2}$ \\ ${ }^{I}$ M.Tech student in EEE Department, NITK, Surathkal, India \\ ${ }^{2}$ Associate Professor in EEE Department, NITK, Surathkal, India
}

\begin{abstract}
In this paper a MV (medium voltage) of $11 \mathrm{KV}$ XLPE (cross linked polyethylene) power cable is implemented in COMSOL MULTIPHYSICS. This software simulates the results based on FEM (Finite Element Method) in order to know the stress effects of electric field in the formation of water trees. Water voids form when there is mechanical damage while laying directly or buried in ducts and water penetrates through the cable sheath. So the impurities fill the cable and result in treeing which develops slowly. The results show the field effect is more at the corners of the ellipse shaped water void which direct radial outwards from the cable axis. This maximum value of electric field causes the formation of channels between the micro cavities which further leads to breakdown.
\end{abstract}

Keywords: COMSOL MULTIPHYSICS, FEM (Finite Element Method), water tree and electric field effect

\section{INTRODUCTION}

XLPE power cables are used in the densely populated areas for the distribution of power to the utilities without any interruption which have less probability of failure and for safety purpose. Water treeing is one of the major concerns for the power cable industry. Researchers have put great efforts to find out the solution for water treeing with improved insulation materials [1]. However practically there is no WTR (water tree retardant material) which qualifies the tests that are not available in international cable specifications [2]. Experimental results by researchers show that conventional XLPE performs better than WTR-XLPE material. Water tree initiates if stress exceeds certain limit when the cables are passed through wet surroundings. Water trees degrade the dielectric strength of the insulation and can spread thorough out the insulation thickness with high moisture content [2-3]. Selection of materials with less permeability to water may delay the occurrence of water treeing [4]. The presence of water voids in the XLPE insulation causes the non uniform electric field to increase and mould the voids into elliptical shape due to polarization effect [5]. Two types of trees are developed which are vented water tree which develops in cable screen as shown in fig 1 and bow tie tree which develops in cable insulation [2]. In this paper a three-core cable is modeled in COMSOL MULTIPHYSICS 3.3a by adding electrostatics, conduction and convection modules with the cable buried in the soil shown in fig.2. Then the electrical parameters such as relative permittivity and thermal parameters such as thermal conductivity, specific heat capacity and density of the respective material used in the cable model. The materials applied are copper conductor, XLPE insulation, lead sheath and void filled with water. The model is designed in order to judge the effects of water voids in the cable insulation. The results of potential and electric field distribution show the causes of water trees.

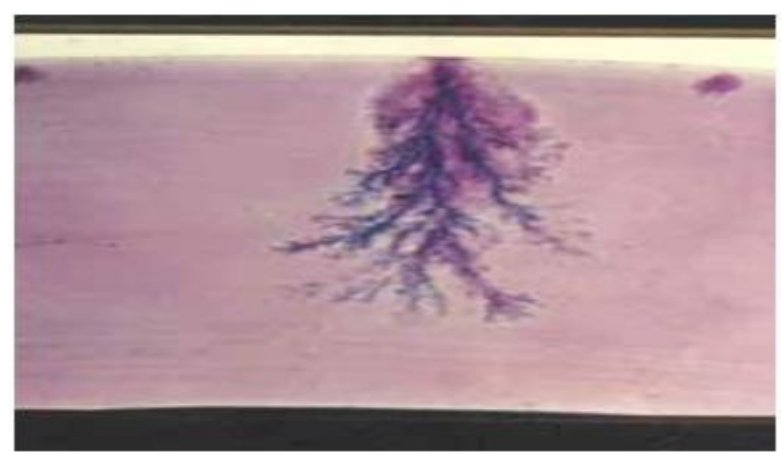

Fig-1: Vented water tree in the cable screen

\section{THEORY}

\subsection{Comsol Multiphysics:}

In COMSOL MULTIPHYSICS software a 2-D model is implemented. It is based on Finite Element Method (FEM) in which the model designed is transformed into a mesh of many elements. It is used to compute the values at every point in the model to get fine results.

The software package has many modules in it such as AC/DC module, heat transfer module. In the present work we have used AC/DC module by adding electrostatics a subdivision in it to determine the potential and electric field distribution in the cable and heat transfer module to determine the heat flux distribution in the cable. 


\subsection{Electrostatics}

COMSOL's electrostatic application modes with sub domain settings solve Poisson's equation [6].

$$
-\nabla \cdot d\left(\varepsilon_{0} \varepsilon_{r} \nabla V\right)=d \rho
$$

Where $\rho$ is the space charge density; $€_{\mathrm{r}}$ is the relative permittivity of applied material.

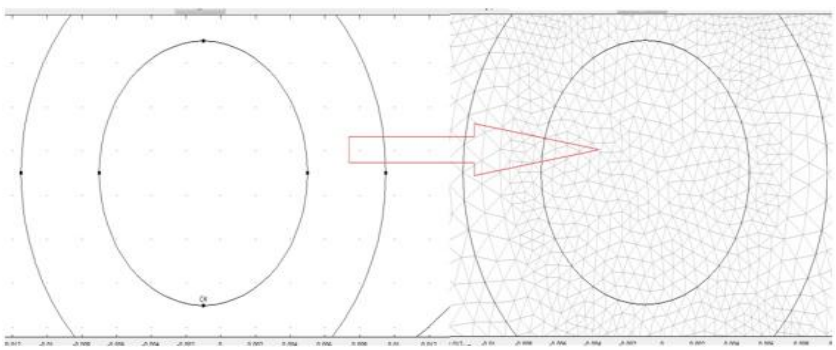

Fig-2(a): Transformation of cable sample to mesh using FEM

The boundary conditions that is to be given is

$$
\text { At sheath } \mathrm{V}=0 \text { (grounded) }
$$

At conductor $\mathrm{V}=V_{m} \sin (w . t)$

By default whatever the voltage we give in the COMSOL MULTIPHYSICS it takes the value as Vm with sinusoidal wave. The voids which are initially in different shapes transform to ellipsoid with the penetration of water in it. Water tree (or chemical trees) formation needs high moisture content. These develop from the protrusions in the layers of cable. This is due to the chemicals that surround the cable. These chemical trees grow and propagate slowly that it may take some months or years to develop. These are influenced by several factors such as voids, electric stress, temperature gradient and ageing. Electron bombardment in the micro cavity may lead to the degradation of the insulation material which reduces the dielectric strength of the material. Water voids are in the direction of field lines radial outwards to that of cable axis [8].

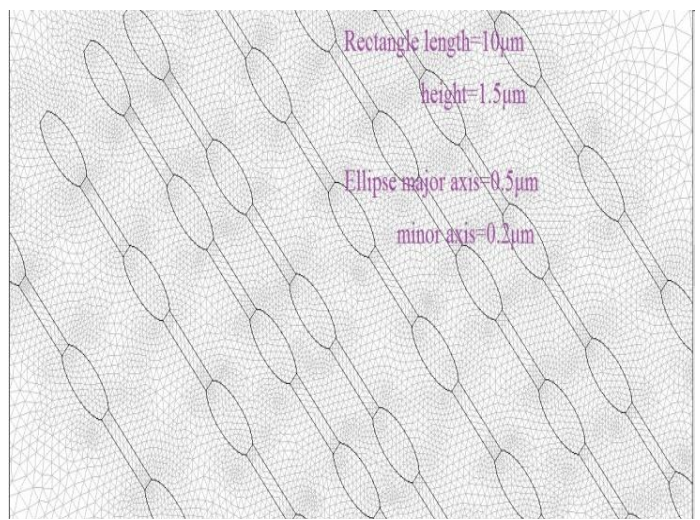

Fig-2(b): Mesh form of water voids with channels
The model of water voids is designed with the ellipse shape with the major axis of $0.5 \mu \mathrm{m}$ and minor axis of $0.2 \mu \mathrm{m}$. With these water voids the electric field increases at the edges of these voids and it persists for a long duration then there are chances for the arc between the voids which creates channels between them which were modeled as rectangular channels with length of $10 \mu \mathrm{m}$ and width of $1.5 \mu \mathrm{m}$. The ellipse is modeled to fit with the rectangular channels.

\section{MODELING PARAMETERS}

Table-1: Cable parameters

\begin{tabular}{|c|c|c|c|c|}
\hline Marameters & $\begin{array}{c}\text { Thermal } \\
\text { conductivity } \\
(\mathbf{W} /(\mathbf{m} . \mathbf{k}))\end{array}$ & $\begin{array}{c}\text { Densit } \\
\mathbf{y} \\
\left(\mathbf{k g} / \mathbf{m}^{\mathbf{3}}\right)\end{array}$ & $\begin{array}{c}\text { Specific } \\
\text { heat } \\
(\mathbf{J} /(\mathbf{k g} \cdot \mathbf{k}))\end{array}$ & $\boldsymbol{\epsilon}_{\mathbf{r}}$ \\
\hline Copper & 400 & 8700 & 385 & 1 \\
\hline XLPE & 0.38 & 2200 & 1900 & 2.2 \\
\hline Lead & 34 & 11370 & 3000 & 8 \\
\hline Air & 0.024 & 1.2 & 1005 & 1 \\
\hline Water & 0.58 & 1000 & 3895 & 80 \\
\hline
\end{tabular}

Table-2: Global expressions

\begin{tabular}{|c|c|c|}
\hline Name & Value & Unit \\
\hline $\mathrm{f}$ & $50[\mathrm{~Hz}]$ & $1 / \mathrm{s}$ \\
\hline $\mathrm{V} 1$ & $11000 \cdot \sin (\omega . \mathrm{t})[\mathrm{V}]$ & $\mathrm{V}$ \\
\hline $\mathrm{V} 2$ & $11000 \cdot \sin (\omega . \mathrm{t}+\theta)[\mathrm{V}]$ & $\mathrm{V}$ \\
\hline $\mathrm{V} 3$ & $11000 \cdot \sin (\omega . \mathrm{t}-\theta)[\mathrm{V}]$ & $\mathrm{V}$ \\
\hline$\theta$ & $120[\mathrm{deg}]$ & degree \\
\hline
\end{tabular}

Table-3: Solver parameters

\begin{tabular}{|l|c|}
\hline Parameter names & $\mathrm{t}$ \\
\hline Parameter values & $0: 0.001: 0.015$ \\
\hline
\end{tabular}

Table-4: Parameters

\begin{tabular}{|c|c|}
\hline Material & $\boldsymbol{\epsilon}_{\mathbf{r}}$ \\
\hline Water & 80 \\
\hline Channel & 16 \\
\hline
\end{tabular}

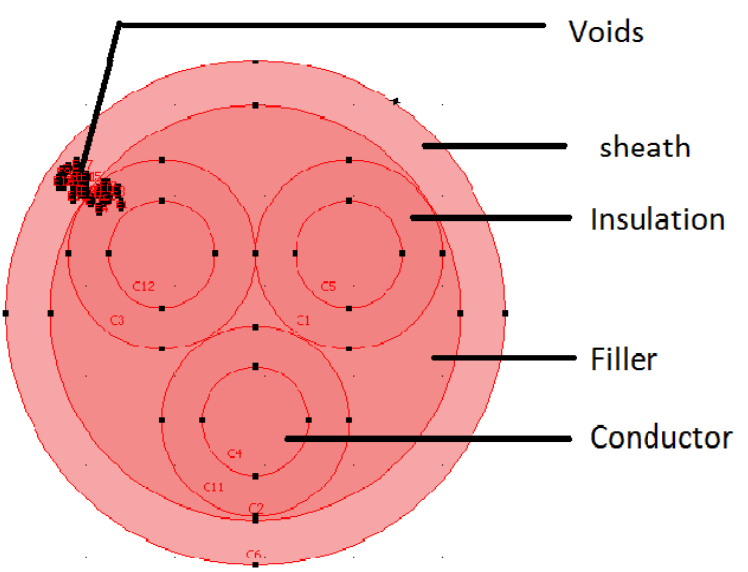

Fig-3: 3-core cable model buried in soil 


\section{RESULTS AND DISCUSSIONS}

The potential distribution of a 3-core cable is shown in the Fig-4(a). The graph shows that the conductor is at same potential. As the distance from the conductor increases the potential value decreases. The potential distribution along the voids is not uniform which is to be linearly decreasing from conductor to sheath.

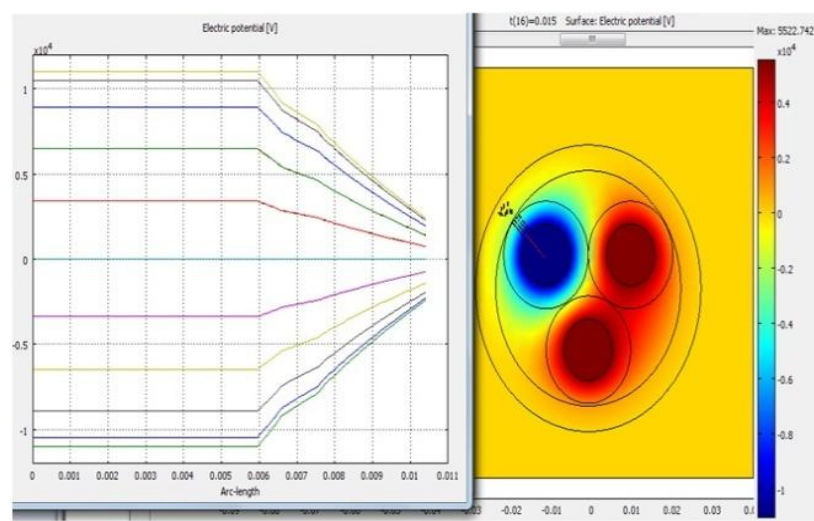

Fig-4(a): Electric potential in 3-core cable with time

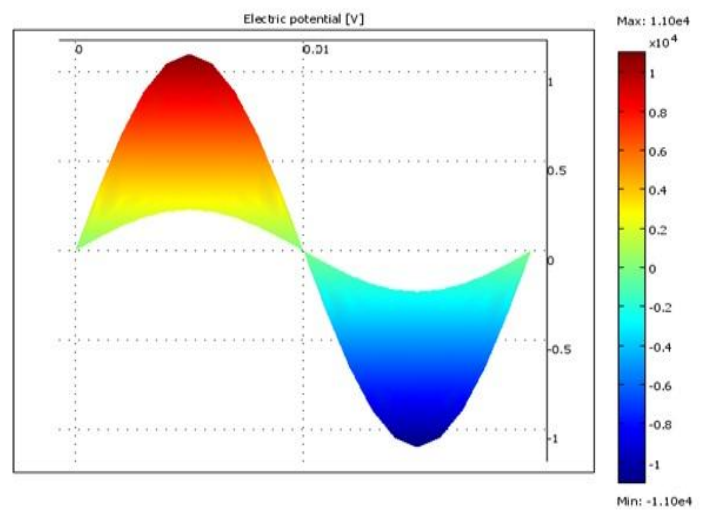

Fig-4(b): Electric potential distribution in the form of sine wave

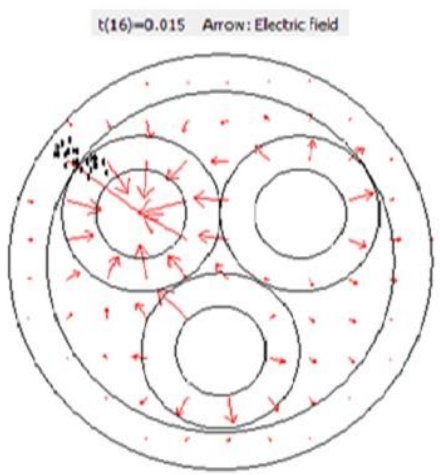

Fig-5(a): Electric flux lines from positive charge to negative charge region
Positive charged particles tend to move to negative charged particles. At $\mathrm{t}=15 \mathrm{~ms}$ phase $\mathrm{A}$ is negatively charge as shown in Fig 4(b). So the electric field lines move from phase B and C which are positively charged to Phase A where the electric field expands and then contracts.
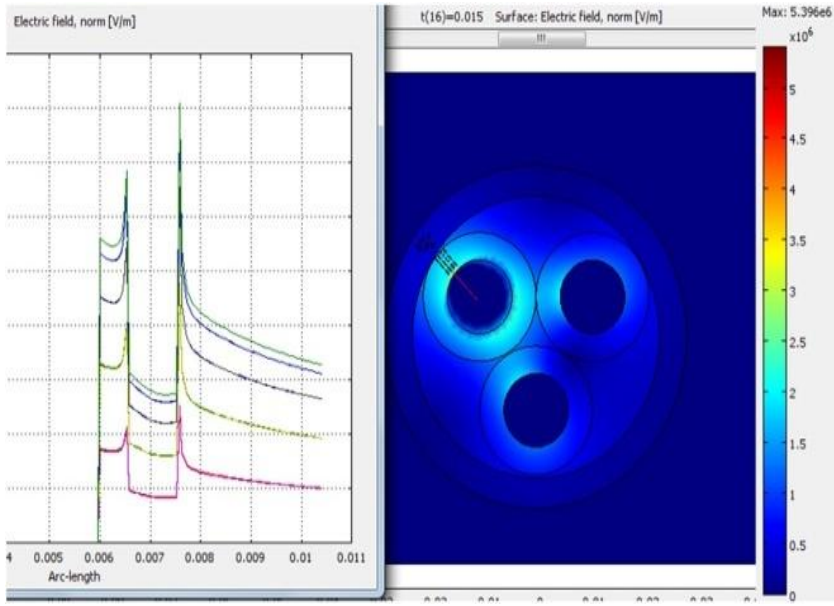

Fig-5(b): Electric field distribution in 3-core cable
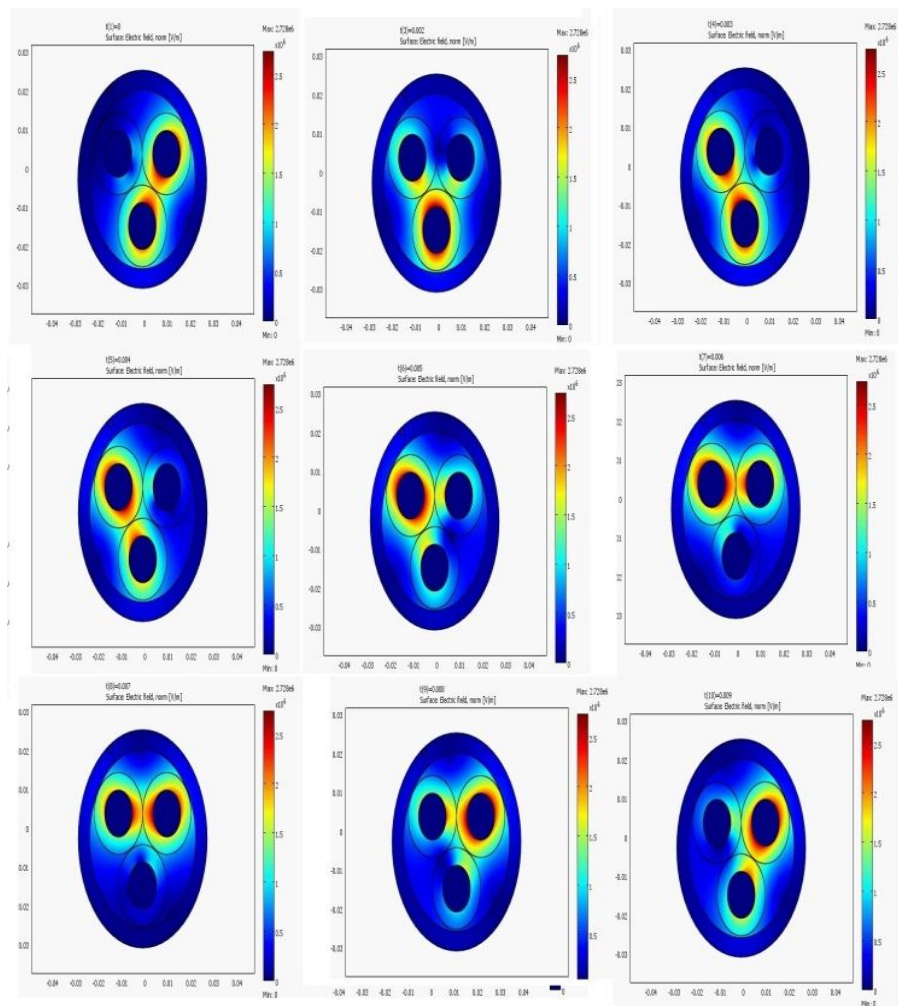

Fig-5(c): Electric field variation with respect to time

The electric field variation with respect to time is shown in Fig-5(c) for the cable from time at $\mathrm{t}=0 \mathrm{~ms}$ to $9 \mathrm{~ms}$ in which the continuous variation of field takes place at power frequency of $50 \mathrm{~Hz}$. 


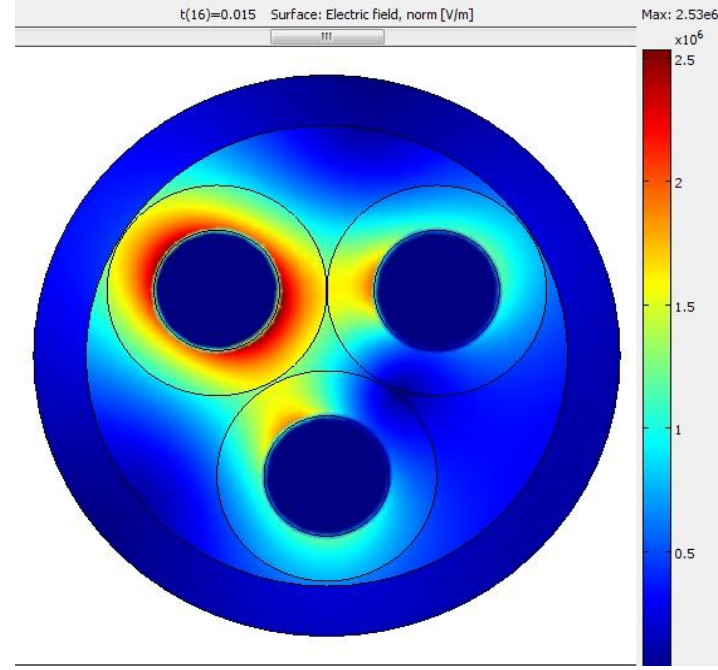

Fig-6(a): Electric field in a power cable without voids

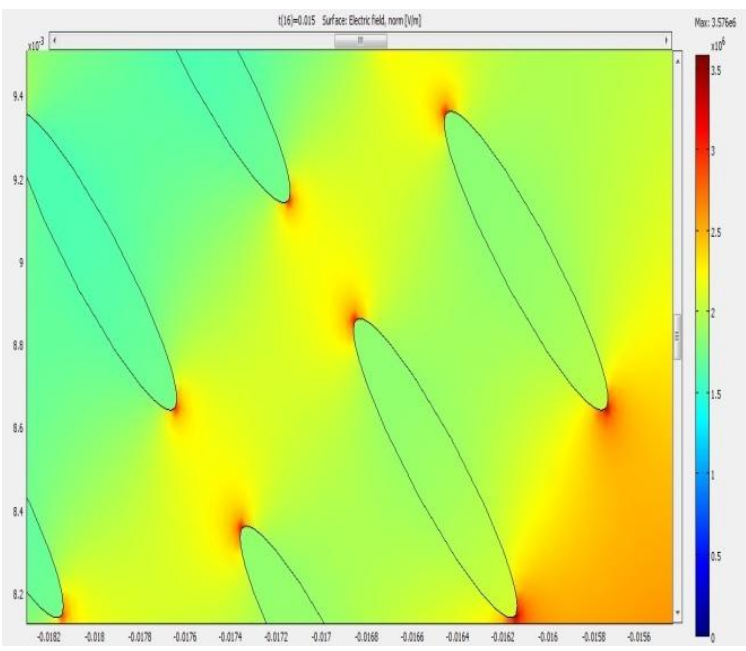

Fig-6(b): Water voids in cable insulation

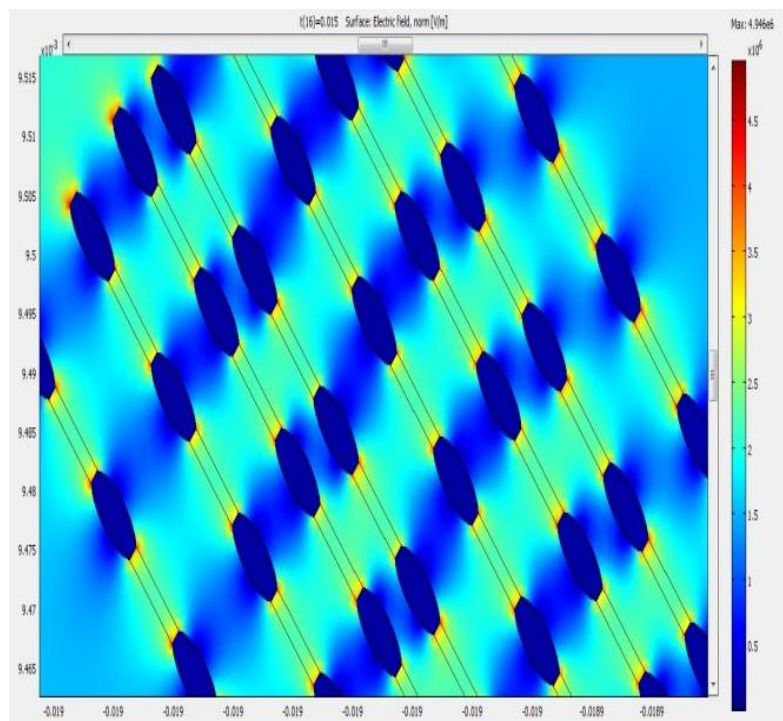

Fig-6(c): Channel formation between water voids

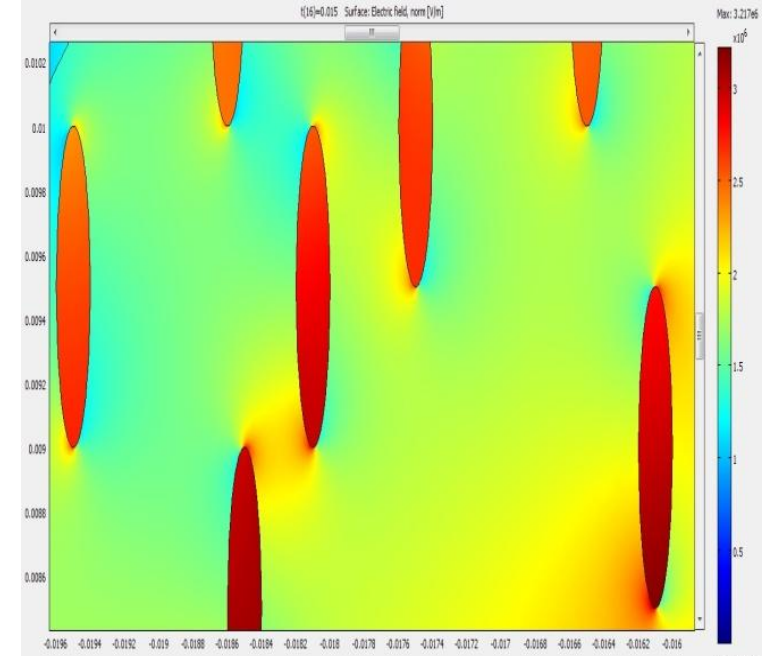

Fig-6(d): Air filled voids in cable insulation

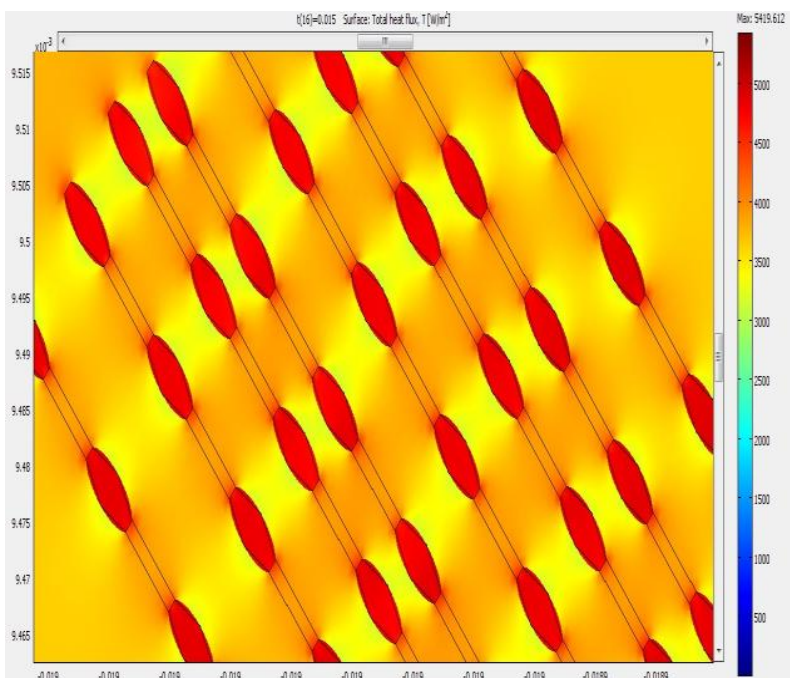

Fig-7(a): Total heat flux distribution in cable insulation with water voids

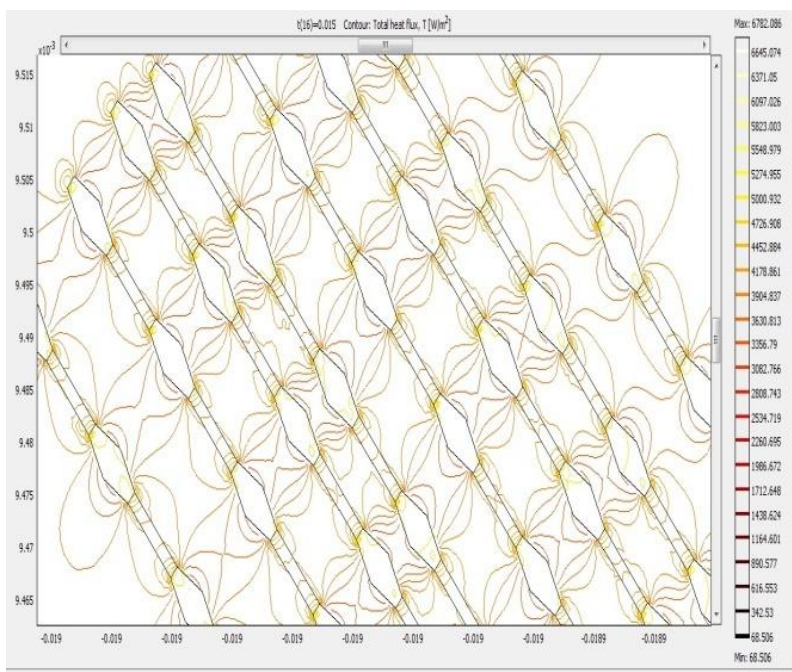

Fig-7(b): Contour plot of total heat flux with water voids 
The electric field distribution in 3-core cable which is operating perfectly is as shown in the Fig-6(a). Here we can observe the value of maximum electric field is around $2.5 \times 10^{6}$ $\mathrm{V} / \mathrm{m}$. This high electric field causes mechanical stress which results in cracks across the insulation. If the voltage stress is increased then the valance electrons in the atoms of the dielectric material are removed. Then there will be availability of free electrons in the insulation material. Due to this the insulation lost its properties and become a conductor at breakdown state. Partial discharges in such cracks may result in electrical breakdown that leads to the formation of treeing. Insulation polymers which are permeable to moisture become harmful.

If we look at the Fig-6(b) we can observe that the electric field in the 3-core cable buried in the soil with water voids. Water trees may occur at low electric fields and takes long time to develop. At $\mathrm{V}=0$ partial discharge may not occur between these voids with water. But at $\mathrm{V}=\mathrm{V}_{\mathrm{m}}$ we can see that there will be formation of channels between these micron size voids which results in water trees which develop slowly without any failure.

As these water voids lined up in the direction of the flux lines radial outwards then we could observe the maximum value of electric field was at the curvature of the ellipse and maximum value rise to $3.5 \times 10^{6} \mathrm{~V} / \mathrm{m}$. This increase in the value is due to the presence of the water voids. There may be formation of channels between these voids which result in treeing as shown in Fig-6(c). This shows the maximum value of electric field increased up to $4.9 \times 10^{6} \mathrm{~V} / \mathrm{m}$. If the electric field is developed for a long time then there is a chance of electrical treeing.

If the voids filled with air then the electric field distribution would be as shown in Fig-6(d). The electric field inside the void is more if we compare with the remaining part of the insulation. This is due to the ionization of air filled voids in the insulation by conduction current in which free electrons are available. These free electrons which are trapped in the void turns to become a heat source [9]. If the free electrons increase with the increase in the electric field then these trapped free electrons in the void leads to breakdown. The total heat flux distribution along the water voids shows that the micro cavity turns into a heat source .This value of heat flux inside the cavity is more compared with the rest of the sample which is shown in Fig-7(a).The contour plot of the total heat flux distribution across the water voids is shown in the Fig-7(b).

Table-5: Results

\begin{tabular}{|c|c|}
\hline $\begin{array}{c}\text { Composition of } \\
\text { voids }\end{array}$ & $\begin{array}{c}\text { Peak value of } \\
\text { Electric field (V/m) }\end{array}$ \\
\hline no voids & $2.5 \times 10^{6}$ \\
\hline Water voids & $3.5 \times 10^{6}$ \\
\hline Voids with channels & $4.9 \times 10^{6}$ \\
\hline Air filled voids & $3.2 \times 10^{6}$ \\
\hline
\end{tabular}

\section{CONCLUSIONS}

The electric field distribution in the cable containing water voids shows that the electric field is high at the curve of the ellipsoidal shaped voids. This causes the formation of channels at this peak value between voids. This results in the formation of water tree that grows slowly without sudden failure. It grows for long time and may eventually cause breakdown of the cable insulation. If the voids are filled with air then the conduction currents cause the voids to become a heat source.

\section{REFERENCES}

[1] Faremo H., and E. lldstad "Water treeing and dielectric loss of WTR-XLPE cable insulation." science, Measurement and Technology, IEEE Proceedings A, vol.140, no.5.IET, 1993.

[2] DuCab "Water tree ageing of polymeric cables" energize - September 2010 - Page 40

[3] Boggs S.A and M.S. Mashikian "Role of semiconducting compounds in water treeing of XLPE cable insulation" IEEE electrical insulation magazine 10 Number 1, 1994: pp. 23-27.

[4] Helleso S. M., V. C. Henoen and S. Hvidsten "Simulation of Water Diffusion in Polymeric Cables Using Finite Element Methods." Electrical Insulation, 2008. ISEI 2008.Conference Record of the 2008 IEEE International Symposium on. IEEE, 2008.

[5] Capaccioli S., et al. "Effect of water inclusions on charge transport and polarization in porous media" Dielectrics and Electrical Insulation, IEEE Transactions on 8.3 (2001): 454-460.

[6] COMSOL Group Ltd., Stockholm, Sweden: Comsol Multiphysics Software Package Version 3.3a. December 2006

[7] Sadiku, Matthew. Elements of electromagnetics (the oxford series in electrical and computer engineering). Oxford University Press, USA, 2004.

[8] Elayyan, H. S. B., and M. H. Abderrazzaq. " Electric field computation in wet cable insulation using finite element approach." Dielectrics and Electrical Insulation, IEEE Transactions on 12.6 (2005): 1125-1133.

[9] Mariut, Larisa "Temperature gradient effect on partial discharge activity-modeling and simulation" Applied and Theoretical Electricity (ICATE), 2012 International Conference on. IEEE, 2012

\section{BIOGRAPHIES}

Aluru Divya Teja has received B. Tech degree in Electrical and Electronics (EEE) from CVR College of Engineering HYD in 2012. He is pursuing his M.Tech in NITK Surathkal, INDIA.

K. Rajagopala is working as an Associate Professor in NITK Surathkal. He has 25 years of teaching experience. 